\title{
INTERPRETACIÓN MULTIFUNCIONAL DEL PÁRRAFO
}

\author{
José MANuel Bustos GisBerT \\ Universidad de Salamanca \\ jbustos@usal.es
}

\begin{abstract}
Resumen
A partir de una revisión de la definición tradicional del párrafo se persigue superar una percepción del mismo que lo identifica como unidad primordialmente estructural. Se plantea una interpretación del párrafo como unidad de construcción discursiva, una herramienta en manos del autor para ahormar el texto. En el diseño del párrafo intervienen consideraciones esenciales referidas a cuatro planos diferentes: configuración temática, organización retórica, distribución visual y procesamiento cognitivo. Se comprueba, pues, que el párrafo cumple funciones diferentes asociadas con estas cuatro variables. Finalmente se evalúa el rendimiento de esa interpretación del párrafo en un corpus de textos escritos redactados por aprendices de composición escrita en dos fases distintas de su aprendizaje.
\end{abstract}

PALABRAS CLAVE: párrafo, texto, análisis textual, expresión escrita.

\begin{abstract}
From a review of the traditional definition of the paragraph we seek to overcome a perception that identifies it as primarily a structural unit. We present an interpretation of the paragraph as a discursive construction unit and a tool in the hands of the author to provide text cohesion. Paragraph design involves key considerations on four different levels: thematic setting, rhetorical organization, visual distribution and cognitive processing. Results show that the paragraph has different functions associated with these four variables. Finally we evaluate the accuracy of this interpretation of the paragraph in a corpus of texts produced by learners of written composition in two distinct phases of their learning.
\end{abstract}

KEY WORDS: paragraph, text, text analysis, written expression.

\section{Introducción: los orígenes de la definición del párrafo}

Las diferentes representaciones del proceso de construcción del texto escrito postulan tres grandes fases para el mismo: planificación o precomposición, redacción y revisión o corrección. Es en la segunda de ellas donde tradicionalmente se aborda el estudio del párrafo y del enunciado como unidades de creación textual. Dedicaremos estas páginas a la primera de ellas desde la perspectiva de nuestra labor habitual dedicada a la formación de escritores noveles. Para ello, comenzaremos nuestro trabajo repasando la interpretación tradicional del párrafo entendido como unidad primordialmente estructural. Desde esta posición plantearemos una interpretación del párrafo como 
unidad de construcción discursiva en cuya configuración intervienen cuatro consideraciones esenciales referidas al texto resultante: configuración temática, organización retórica, distribución visual y procesamiento cognitivo.

Con demasiada frecuencia, se parte de una percepción abiertamente canónica del párrafo. Así, se interpreta como unidad de sentido con una estructura formal fija y preconcebida. Se asume como cierta una descripción normativa de escasa relación con la realidad discursiva. Son, sin embargo, posiciones que aún hoy alcanzan eco, especialmente en determinados manuales dedicados a la enseñanza de la redacción y desde posiciones enormemente restrictivas del fenómeno de la comunicación escrita. En palabras de Hayes (2003):

I intend to suggest that in an age immersed in Thomas Kuhn and Nietzsche, it is pedagogically irresponsible, rather absurd, and counter to our educational goals to continue to follow a pedagogical approach that distinguishes form from thought, and which reduces writing instruction to set formulas and matters of superficial correctness.

En el mismo trabajo, Hayes retrasa hasta el siglo XIX el origen de esa interpretación de la unidad: es Alexander Bain quien se plantea el párrafo como una unidad retórica sometida a una regulación predefinida: en su percepción el párrafo tiene una organización similar a la de la oración, y comparte con ella tres características esenciales: coherencia, unidad y desarrollo:

Bain asserted that the paragraph is also characterized by three features, coherence, unity and development. Bain spent the most ink on the subject of coherence, taking care to list the various conjunctions and connectives that can be used to show the relationships between the clauses and sentences within the paragraph; and emphasizing the importance of parallel structure in sentences that illustrate the same idea. Unity, "which implies a definite purpose, and forbids digressions and irrelevant matter," is another prominent consideration. The third is development (which subsequent current-traditionalists renamed mass or proportion), meaning that the paragraph topic is expanded upon sufficiently to satisfy the reader, and the mass of the paragraph is in proportion to its importance to the composition's overall purpose.

Bain (1871) propone 6 reglas fundamentales en la construcción del párrafo. Son las siguientes:

- Cada oración debe estar relacionada con la que le precede.

- Pensamiento paralelo debe emplear estructuras paralelas.

- La primera oración de un párrafo debe indicar el tema del mismo.

- Cada frase debe estar correctamente situada dentro del párrafo. 
- El párrafo debe demostrar unidad.

- Las partes principales y subordinadas deben estar adecuadamente dispuestas.

Tales tesis se han ido repitiendo en lo esencial a lo largo del siglo XX. Así, Harris (1952) defiende que el párrafo se compone de una frase tópica y de su desarrollo; la posición de la primera dependería de que se trate de unidades de construcciones inductivas y deductivas. En la misma línea cabe clasificar la propuesta de Toulmin (1958). En su opinión, el párrafo se conforma sobre la base de la combinación de tres constituyentes. El primero se denomina Afirmación, y en él se incluye la idea principal. El segundo es la Información, donde se incorporan los datos que la apoyan. Finalmente, el tercero es la Garantía, en la que se evalúa la importancia de la información.

Esta percepción no está tan lejos de muchas de las que se mantienen en épocas más cercanas, sustentadas en la idea de que el párrafo se compone de una frase tópica y un desarrollo de la misma. Así ocurre con la postura asumida desde la Tagmémica, representada por Longacre (1976, 1979 y 1980): el párrafo es una unidad estructural de desarrollo del discurso ubicada en un espacio intermedio entre el texto y la oración. Se trata, pues, de una unidad esencialmente gramatical compuesta de dos constituyentes semánticos, que denomina tópico y expansión. Según la naturaleza de uno y otra, plantea la existencia, por un lado, de zonas nucleares y zonas periféricas dentro de la unidad; y por otro, de párrafos abiertos y cerrados según la naturaleza conceptual de la segunda sección. Su interpretación le permite incluso proponer un procedimiento destinado a la identificación de tipos de párrafo sobre la base de su configuración gramatical.

Otros investigadores han relativizado, sin negarla abiertamente, la estructuración canónica del párrafo. Así, Le (1999 y 2004) defiende que el párrafo se utiliza para construir la coherencia textual mediante una unidad superior a la oración. A esta la denomina base macroestructural. Se trata de unidades de análisis supraoracional definidas formalmente, que suelen coincidir, aunque no siempre, con el párrafo entendido como unidad gráfica, y se delimitan en el texto mediante un análisis sobre la base de las relaciones semánticas establecidas entre las partes: estas pueden ser de coordinación, subordinación o superordinación con respecto de la frase tópico del párrafo, que va ubicada al principio de la base. Por otra parte, Smith (2008) defiende que la frase tópico existe aunque no se explicite en el párrafo: su frecuencia de aparición depende, de un lado, de una decisión estilística por parte de los autores; y, de otro, de la longitud de los párrafos: los cortos no suelen tenerla porque habitualmente la comparten con el inmediatamente anterior. En su percepción, es bueno instruir a los escritores noveles para que la incluyan porque su frecuencia de aparición está en el 70\% de los casos. 
Dentro de los estudios vinculados al párrafo en el marco de la construcción de textos en español también identificamos investigadores que postulan la existencia de una estructura de párrafo sustentada en la existencia de una frase tópico y un desarrollo. Así ocurre con Olivares (1982), García Berrio y Albadalejo (1983) y Fuentes (1996). En todos los casos se tienen muy presentes las aportaciones de la Tagmémica y se defiende que un párrafo es una secuencia de oraciones con un mismo tópico. Por su parte, González Cobas (2002), ha dedicado un extensísimo trabajo al estudio del tópico de párrafo en Alfonso X. En él propone una definición de este espinoso concepto:

Para nosotros el tópico de párrafo es aquel tópico con que se inicia el párrafo, si es que es tópico el elemento que se halla en esa posición. Somos conscientes de que esta clase de tópico también forma parte de una oración, por estar compuestos los párrafos de un número indeterminado de oraciones, pero ello no impide que posea ciertas características que aconsejan diferenciarlo del tópico oracional (págs. 74).

La propuesta nos resulta insatisfactoria en la medida en que solo se plantea establecer diferencias con el llamado tópico oracional, y no entra a discutir la necesidad o no de su presencia en el párrafo. Igualmente dudoso nos parece asumir que el tópico de párrafo forma parte de una oración; entre otras cosas porque está mezclando unidades de muy distinta naturaleza. En cualquier caso, sus apreciaciones debemos evaluarlas desde la perspectiva de un estudio de la construcción textual de carácter diacrónico, cuestión esta que se aleja de los propósitos de nuestro trabajo.

Por fin, tampoco está muy alejada de todos ellos la percepción de Sorókina (2008a), quien defiende que el párrafo se organiza de forma similar a un texto, en tanto que tiene introducción, desarrollo y conclusión, partes a las que denomina apertura, esclarecimiento y desenlace: en la primera, que coincide en lo esencial con el tópico de párrafo, se inicia la idea que se va a desarrollar y con ella el párrafo; en la segunda parte se aclara el concepto; en la tercera se finaliza. Asimismo (Sorokina, 2008b), identifica el texto como una suma de párrafos entendidos como cadenas de oraciones. Cada una de ellas equivale a un mini texto: goza de una articulación lógica con estructura rigurosa dependiente de su función en el marco textual y aporta una idea independiente y relativamente completa.

Las principales críticas a esta percepción del párrafo como unidad textual dotada de una estructura perfectamente identificada e identificable se establecen desde diversas perspectivas. La primera tiene que ver con la existencia misma del tópico de párrafo. En ese sentido, se han realizado diversos estudios al respecto, que, sin embargo, han aportado datos muy divergentes. Así, Braddock (1974) en un célebre trabajo de contestación a las tesis defendidas desde Bain, afirma que solo un 13\% de los párrafos por él analizados comienza por una frase tópico. En la misma dirección, Larsen (1976) afirma que los 
párrafos a menudo carecen de frase tópica y, desarrollan más de un concepto. Enfrente, Popken (1987) eleva la cifra de párrafos con frase tópica al 78\%, y Smith (2008), sobre la base de los análisis de este último, postula la aparición en un 70\%. Dejamos para el final la interesantísima aportación de Sánchez Escobar (1996): analiza un corpus de artículos expositivos redactados en español y en inglés a partir de los conceptos de oración temática y organización conceptual: coordinada, subordinada o digresiva. Concluye que los textos ingleses usan habitualmente una oración temática generadora de párrafos, pero que tal tendencia no se observa en los redactados en castellano: los autores españoles no están coaccionados por una oración temática inicial reguladora; por ello, la construcción de los párrafos es más libre. Paralelamente, la organización conceptual es más rica, menos metódica y más digresiva.

Con todo, las aportaciones de unos y otros al respecto nos parecen de una utilidad limitada en tanto que los corpus de partida demuestran escasa fiabilidad. Y esa falta de fiabilidad tiene que ver con razones cuantitativas y también cualitativas: el tamaño de las muestras suele ser muy limitado y, al mismo tiempo, representa un único tipo textual, el expositivo.

Otra línea crítica con la interpretación estructural la descubrimos en una serie de estudios realizados sobre la base de la división de textos en párrafos. En ellos se parte de una hipótesis más que razonable: si el párrafo tiene una estructura preestablecida, identificada e identificable, es lógico pensar que un lector al que se le escondiera la división de párrafos realizada originalmente por el autor podría reconstruirla sin excesivas dificultades. Uno de los experimentos más relevantes lo llevó a cabo Stern (1976). Parte de un texto expositivo de quinientas palabras al que elimina las marcas de párrafo y pide a un grupo de más de cien profesores de inglés que las reconstruyan: el grupo completa la tarea en aproximadamente quince minutos. Solo cinco de ellos dividen tal y como lo hacía el autor en el texto original. El resto plantea propuestas entre dos y cinco párrafos, y muchas de ellas resultan, en su opinión, igualmente aceptables. De ahí concluye que el párrafo no se puede interpretar como una unidad lógica de estructura cerrada, en la que no necesariamente se detecta una frase tópica ni tampoco desarrolla en todos los casos una idea única. Por todo ello, es erróneo un acercamiento didáctico que le convierte en una auténtica fórmula ${ }^{1}$.

\footnotetext{
${ }^{1}$ En una línea similar estaría el trabajo de Stark (1988), quien concluye que las divisiones de párrafo se insertan de modo impredecible: solo si están se pueden identificar. El lector interesado puede también consultar Bond y Hayes (1984) y Ji (2008).
} 
En tercer lugar, tampoco se ha valorado, salvo en el caso de Sánchez Escobar, si el párrafo es una unidad de estructura universal, como sucede con el texto, o si por el contrario su construcción se asocia a tradiciones retóricas vinculadas a lenguas y culturas concretas. En otras palabras, si lo afirmado por Bain es exclusivo de la lengua inglesa: el trabajo de Sánchez Escobar parece apuntar en tal dirección. Del mismo modo, habrá que plantearse si la construcción del párrafo ofrece también variaciones de naturaleza diacrónica y diafásica. En este sentido, es oportuno recordar, y seguimos ahora a Stern (1976), que la construcción de párrafos también puede obedecer a cuestiones de moda y de convención de género textual. En palabras de este autor se puede demostrar que los párrafos han variado de longitud de manera perceptible en los últimos 100 años.

Ante este estado de cosas es conveniente ahora recordar los acertados juicios de Knoblauch (1981). Parte de la necesidad de liberarse de los juicios de valor y de la dificultad de hacer generalizaciones que resulten relevantes. Propone como ejemplo la afirmación de que los párrafos incluyen una frase tópico y nos recuerda que Larsen (1976) ha demostrado que muy a menudo esa frase no aparece. Es cierto, entonces, que muchos párrafos tienen frase tópico, pero no necesariamente tiene que aparecer. Asimismo, afirma que establecer demasiadas condiciones para la consideración del párrafo conduciría a detectar un número mayor de ejemplos que las contradicen frente al de aquellos que las cumplen. Termina recordando que la escritura no siempre se ha distribuido en párrafos, e incluso desde que se utilizan han tenido funciones diferentes según los autores que los utilizan. Son especialmente importantes las palabras finales de su trabajo:

I would conclude by insisting again that paragraphs can enjoy structural integrity any time we want them to, just as they can feature topic sentences. But we must be careful to distinguish between what writing may look like under diverse conditions and what it must manifest by way of structural characteristics in order to be called writing, in a meaningful sense, at all. Historically, writing has not always been displayed as paragraphs. And even when it has been so displayed, its subdivisions have had different functions for different writers. Perhaps only two structural elements beyond the sentence are prerequisite to meaningful written discourse: the first is some pattern of consecutive entailments within its linearly arranged statements so that a reader can perceive logico-grammatical connections between any two adjacent statements or between any one statement and the context preceding it. The second is a pattern of repetitions that remind the reader about larger judgments regarding focus and emphasis throughout an evolving discourse. Neither of these structural elements is simple and neither has been explored in anything approaching adequate detail (págs. 6061). 
Y es que para Knoblauch, la organización de párrafos no surge de una planificación estructural resuelta antes de empezar a escribir. Es una decisión tomada por el escritor sobre la marcha. Surge de la impresión de que el párrafo ya es bastante largo para cortar o de la evidencia de que ha habido un cambio claro en la dirección argumentativa. La percepción de su unidad es, pues, un descubrimiento gradual, incluso accidental, en el proceso de escritura. A fin de cuentas, tal postura coincide con la de Coulthard (1985): el párrafo no se puede caracterizar sobre la base de combinaciones posibles e imposibles. La agrupación de frases en un párrafo depende de razones estilísticas y de contenido, pero no de argumentos gramaticales.

Con frecuencia la crítica ha tenido dificultades a la hora de establecer las relaciones entre las distintas unidades lingüísticas, las propias del discurso y las involucradas en su construcción En otras palabras, resulta complejo establecer los campos de aplicación de la oración por un lado; el párrafo y el enunciado en segundo lugar; y, finalmente, la secuencia textual y el texto. Es frecuente que unas unidades y otras aparezcan mezcladas en un mismo modelo interpretativo cuando se refieren a planos de análisis diferentes. La insuficiencia de la interpretación estructural del párrafo deriva, a nuestro modo de ver, de su propia naturaleza. No es esta una unidad formal por encima de la oración; de hecho, resulta difícil demostrar regularidades estructurales para unidades superiores a la oración (Haliday y Hassan, 1976). Más aún, el texto no es una macro unidad formal construido con otras menores. En palabras de Haliday y Hassan, un texto no consiste en oraciones; está realizado por o codificado por oraciones. Si lo entendemos así, no esperaremos encontrar el mismo tipo de integración estructural entre las partes de un texto como la que encontramos entre las partes de una oración. El texto es una unidad de lengua en uso: una palabra, un sintagma, una oración, un conjunto de oraciones puede configurar un texto. Su naturaleza formal nada tiene que ver con su función comunicativa. Por ello, exige para su definición parámetros distintos.

Pero el párrafo tampoco es una unidad discursiva en términos de macro y superestructura como propone Le. Las divisiones superestructurales se asocian a las secuencias textuales. Existen antes en la conciencia del autor y a ellas se remite en el proceso de construcción. Las unidades textuales surgen de una organización discursiva previa a la escritura y se asocian a la organización secuencial prevista, que lleva aparejada la construcción de macroestructuras y superestructuras coherentes con las secuencias tipológicas implicadas. Cuando Sorókina define el párrafo con una suerte de minitexto, está confundiendo unidades textuales (secuencia) con unidades de construcción (párrafo).

Como herramienta de articulación a disposición del autor, este disfruta de un considerable grado de libertad a la hora de fijar sus límites. Pero esa libertad no es completa, puesto que la configuración de párrafos puede (que no debe) estar también limitado por 
convenciones vinculadas a la naturaleza del género textual implicado en la construcción del texto. El género, en tanto que expresión del texto en el nivel superficial condiciona con frecuencia ese segundo nivel de construcción ${ }^{2}$. Del mismo modo que el modo de organizar un texto y las valoraciones de esa organización depende de las lenguas y las culturas. Así, texto y superestructura se analizan en términos de competencia general de la comunicación, mientras que género y párrafo se asocian a una capacidad particular en un entorno lingüístico y cultural específico. Coincidimos, pues, en lo esencial con Girón Alconchel (1981) cuando afirma que el párrafo depende de la época, el género textual y el estilo de cada autor. A esas tres condiciones añadimos la lengua y la cultura.

Los párrafos son, entonces, unidades de la construcción del discurso, propias del proceso de creación textual y resultado del mismo, y que se sitúan entre el enunciado y el texto ${ }^{3}$. Entendemos, a su vez, por enunciado la unidad informativa mínima utilizada en la construcción textual, base de la cohesión discursiva y que se encuentra delimitado por la puntuación extraoracional. Muy acertada es la percepción de Garachana y Montolío (2000), que interpretan el párrafo como herramienta de parcelación del contenido textual:

Los párrafos, son, pues, las moléculas -compuestas a su vez por átomos, que serían las oraciones- que constituyen la unidad que llamamos texto. ${ }^{4}$ (pág. 73)

\section{Percepción multifuncional del párrafo}

Así pues, el párrafo se presenta como unidad de construcción textual que se configura en el proceso de la composición sobre la base de la combinación de otras unidades menores, que son los enunciados. En su construcción, intervienen de manera fundamental el tipo de secuencia textual del que se trata y el género del discurso al que nos ceñimos en el momento de la creación del texto. No es, por tanto, una decisión previa a la escritura, sino que se inserta en el proceso mismo de redacción. No se trata, entonces, de una unidad preconcebida.

Se trata de una unidad de configuración discursiva: una herramienta en manos del autor/emisor para ahormar el texto. Y esa distribución de la información contenida se plasma en cuatro niveles: temático, retórico, visual y cognitivo. De ahí, la necesidad de proponer una interpretación multifuncional del párrafo.

\footnotetext{
${ }^{2}$ Así lo apunta acertadamente Sorókina (2008a).

${ }^{3}$ Según Crystal (1992), el párrafo es una unidad de discurso entre la frase y el texto.

${ }^{4}$ Más allá de que nos parezca poco justificado el uso del término oraciones.
} 


\subsection{Dimensiones temática y retórica}

Es muy frecuente leer definiciones de párrafo que lo identifican como unidad de significado. Así, Brooks y Warren (1949) lo definen como unidad semántica. En una línea similar, Toulmin (1958) afirma que el párrafo es una unidad de sentido fruto de la combinación de varios conceptos semánticamente convergentes. Estas percepciones aparecen repetidas en numerosos trabajos mucho más cercanos a nuestro tiempo. Por solo citar algunos cabe recordar que Longacre (1979) defiende la unidad significativa del párrafo; en su opinión, toda la información contenido gira en torno a un concepto, a un personaje, etc. En la misma línea, Serafini (1989) postula que a cada párrafo le corresponde una sola idea. Por su parte, Cassany (1995) lo define como un conjunto de frases que desarrolla un tema, lo que lo convierte en una unidad intermedia significativa. Del mismo modo, Garachana y Montolío (2000) lo interpretan como unidad de sentido: un párrafo desarrolla una idea. Terminamos este breve repaso con Martínez (2008), para quien las oraciones del párrafo deben estar relacionadas significativamente.

Podríamos asumir sin ninguna dificultad que son esencialmente ciertas todas las afirmaciones recogidas más arriba, por más que haya voces que no estén de acuerdo, como es el caso de Larsen (1976), para quien a menudo los párrafos no son más que series de oraciones de conexión no muy evidente y que se forman de manera accidental. Pero el problema de fondo es la propia indefinición de la propuesta. Un párrafo desarrolla una idea, un concepto. El significado mismo de idea es tremendamente impreciso: puede ser sencilla, pero también compleja; puede ser simple, y también compuesta; puede ser fácilmente explicable o expositivamente muy prolija. Tanto, que una idea se puede desarrollar en uno, en dos o en mil párrafos. Tomemos como ejemplo la obra de S. Pinker que lleva por título El instinto del lenguaje. En la contracubierta se nos explica el sentido del título:

Tal como expresa el título, la tesis principal de este libro es que el lenguaje constituye un instinto humano, incorporado al cerebro por la evolución, del mismo modo que tejer las telas en las arañas o el canto en las aves.

Evidentemente estamos ante una idea, que se desarrolla en 500 páginas y multitud de párrafos. Así pues, el concepto idea no es útil para indicar el volumen de información que ha de incluirse en un párrafo. Y si no podemos delimitar el concepto, tampoco podemos evaluar si los párrafos cumplen o no esa función de manera adecuada.

El párrafo es una unidad significativa en tanto que integra un conjunto de enunciados relacionados entre sí por el contenido (Calsamiglia y Tusón, 1999). Por lo mismo, Givon (1984) defiende que el párrafo debe mostrar unidad de tiempo, de acción, de lugar y de participantes Esto lo convierte en una unidad informativa compleja. Y esa 
información compleja podrá coincidir o no con una idea completa. Lo esencial no es si el significado desarrollado es completo y cerrado, sino su propia naturaleza compuesta. Y esa característica se plasma en su propia coherencia interna. Como bien apunta Núñez Ladevéze (1997), el contenido del párrafo no es expresable en una sola relación predicativa; por ello, la integración de varios conceptos en un párrafo resulta mucho menos sencilla desde el punto de vista de la coherencia interna. Efectivamente consideramos más adecuado interpretar el párrafo desde su complejidad estructural y desde su unidad temática. En ello coinciden Garcia Berrio y Albadalejo (1983), quienes lo interpretan como secuencia de oraciones con el mismo tópico; Fuentes (1996), cuando lo presenta como un conjunto de enunciados con unidad tópica; y González Cobas (2002), para quien el párrafo es una unidad temática con coherencia interna. Sin embargo, es una unidad de sentido que no tiene por qué agotar el concepto en cuestión. Volvemos a apoyar nuestra tesis en Núñez Ladevéze: se trata de una unidad semánticamente compleja, pero no por ello necesita estar temáticamente completa porque puede ser ampliada; por ejemplo, en otro párrafo. De hecho, el cambio de párrafo supone una ruptura en la continuidad de la coherencia (González Cobas, 2002).

Lo esencial en el párrafo es que se trata de una unidad de coherencia conceptual. En ese sentido, nos parece que acierta De la Fuente (2007) cuando afirma que el objeto de la fragmentación del texto es facilitar la lectura presentando segmentos coherentes y asimilables. Sin embargo, como hemos apuntado más arriba, el párrafo no agota necesariamente una idea. Por todo ello, es una decisión del autor a la hora de establecer vínculos informativos más allá del enunciado entre varios conceptos semánticamente convergentes. Al fin y al cabo, evidencia ante el lector un nivel de relación más íntima entre varios enunciados 5 . La distribución en párrafos persigue condicionar la comprensión por parte del lector.

De todo ello se deduce una dimensión nueva del párrafo: en palabras de Stern (1972), una parte del texto se convierte en unidad independiente porque así lo decide el autor; estamos, entonces ante una elección retórica, y no resultado de la aplicación de una regla de naturaleza estructural. Se trata, pues, de una unidad funcional cuyos límites en absoluto son claros, lo cual la convierte en un instrumento flexible en manos del autor con una función esencialmente expresiva. Así, los párrafos se construyen de manera a priori impredecible (Stark, 1988): son ubicados por razones de énfasis retórico. El párrafo, en tanto que producto de la intención del autor, explicita relaciones conceptuales en los niveles micro y macro. De ese modo, condiciona la línea interpretativa. El

\footnotetext{
${ }^{5}$ Véase Crystal (1992).
} 
autor decide crear unos u otros conceptos complejos de acuerdo con sus objetivos discursivos.

\subsection{Dimensión visual}

Frente a esta percepción del párrafo asociada a su contenido, discurre otra que destaca la imagen visual de esta unidad y que pone el acento en la extensión del párrafo. Tal postura ha sido articulada en la escuela behaviorista (Bolinger, 1946). Se convierte entonces en una interpretación cuantitativa de esta unidad.

Por esta dirección se ha establecido una compleja discusión referida a los efectos derivados de la mayor o menor extensión de los párrafos. Así, Lázaro Carreter (1979) llega a afirmar que el párrafo carece de extensión fija, pero que el largo inhibe y asusta al lector ${ }^{6}$. Por su parte, Stern (1972) defiende que la división en párrafos cortos o largos se asocia al tono del texto: los cortos aceleran el ritmo y aligeran la página, mientras que los largos la hacen más pesada. Algunas de las opiniones vertidas resultan un tanto impresionistas, pero sí es cierto que la longitud del párrafo genera expectativas de lectura en términos de densidad o de ligereza conceptual.

Cassany (1995) postula una percepción abiertamente visual de la escritura y llega a afirmar que es un error de redacción mezclar párrafos cortos y largos:

En general, el aspecto visual parece imponerse a las necesidades internas de extensión. Lo que importa ante todo es que página y párrafo ofrezcan una buena imagen e inviten a la lectura [...]. Por tanto, la recomendación más sensata es que cada página tenga entre tres y ocho párrafos, y que cada uno contenga entre tres y cuatro frases, aceptando siempre todas las excepciones justificadas que haga falta. Resulta difícil y peligroso reducir una recomendación a cifras absolutas. (pág. 86)

La tesis de que los párrafos deben ser cuantitativamente homogéneos tampoco es muy sostenible. Por razones obvias: un texto transmite una determinada información que hemos definido como compleja. Para construirla, hacemos uso de los párrafos, en tanto que cada uno de ellos prefigura una unidad, que es en cierto modo un segmento del total. ¿Es necesario que todas esas secciones sean cuantitativamente homogéneas? Está claro que la respuesta ha de ser negativa. El propio Cassany es consciente de la

\footnotetext{
${ }^{6}$ En la misma dirección cabe citar los trabajos de Quirk et alii (1972) y Werlich (1976). Desde una posición más ecléctica, Figuera (2001) defiende que el párrafo se organiza en tres dimensiones: visual, estructural (uno o más enunciados) y semántica (ideas principales y secundarias). También encontramos esa percepción en Pérez Juliá (1998).
} 
poca justificación de sus afirmaciones, hasta el punto de concluir que su percepción no es más que una recomendación que no ha de seguirse al pie de la letra. Sugiere entre tres y ocho párrafos por página, como si fueran cifras cercanas. Sin embargo, sólo entre tres y cuatro frases por párrafo. El convencimiento interno que traslucen estas afirmaciones parece escaso. Una cosa es hacer recomendaciones a escritores noveles en el proceso de adquisición de la competencia escritora y otra es definir el párrafo desde parámetros visuales. Por supuesto que estamos de acuerdo en marcar la extensión de los párrafos con una intención didáctica, pero este hecho no puede, en ningún caso, extrapolarse en términos conceptuales. Pongamos un ejemplo con un texto que hace ya unos años, Javier Marías escribió en El Semanal. Hablaba sobre la guerra de los Balcanes?:

\section{OBEDIENCIAS ASESINAS}

Venía hace unas semanas en los periódicos: un soldado serbobosnio de veinticinco años, llamado Drazen Erdemovic, al que se juzga por crímenes de guerra ante el Tribunal Internacional de La Haya para la antigua Yugoslavia, se declaró culpable de haber asesinado a centenares de bosnios musulmanes el pasado julio en el enclave de Srebrenica. La noticia iba ilustrada por su fotografía, un joven de aspecto enteramente normal o más bien agradable, con la mirada perdida y los labios prietos de quien está rumiando sus pensamientos.

Según la noticia, el hombre confesó con lágrimas en los ojos y explicó que se vio obligado a matar, ya que, de haberse negado, los serbios lo habrían pasado también a él por las armas. «Si sientes pena por los musulmanes», dice que le dijeron, "ponte también en la fila». Erdemovic añadió que temía no sólo por su suerte, sino por la de su mujer y su hijo de corta edad si se negaba a cumplir la orden de disparar. A este joven lo espera una probable condena de cárcel a perpetuidad, aunque el juez, tras oírle, convocó una nueva sesión del juicio para determinar las posibles circunstancias atenuantes que podrían aplicarse al procesado. Eso quiere decir, supongo, que en principio el magistrado creyó las palabras de Erdemovic.

Y si las creyó, me pregunto por qué ese juicio sigue adelante, a la vez que compruebo que si se suspendiera y se exonerara al reo y se sobreseyera el caso, yo mismo me escandalizaría y pensaría que había gato encerrado y farsa. No es ésta una cuestión fácil, la de la «obediencia debida». Si no estoy mal informado, creo que en la actualidad la excusa de haberse limitado a cumplir órdenes no sirve para exculpar a quien cumpliera unas órdenes claramente delictivas o criminales.

\footnotetext{
${ }^{7}$ Recogido en J. Marías (1997): Mano de Sombra. Madrid: Alfaguara, págs. 265-267.
} 
Pero en una guerra... A diferencia de Pérez Reverte, yo no he visto ninguna, o sólo las de las películas. Pero recuerdo haber oído en una de ellas -tal vez Senderos de gloria de Kubrick, o El sargento York de Hawks, en todo caso era de la Guerra del 14- unas frases que me parecieron muy verosímiles y que venían a decir lo siguiente: «Si los soldados atacan en una batalla, si salen de sus trincheras y corren como locos hacia unos tipos que los están enfilando como a conejos, no es porque en esos momentos estén henchidos de amor a su patria, ni convencidos de que la suerte de sus familias depende de que ellos tomen un montículo, ni porque los impulse el odio, ni siquiera porque vean con claridad que o matan al enemigo o serán muertos por él. A la hora de la verdad nada de eso tiene la suficiente fuerza para hacer que unos hombres se arrojen al precipicio. Lo hacen sólo porque temen aún más a quienes tienen detrás, a sus superiores, y porque saben que si avanzan su muerte es probable, pero segura si retroceden».

Yo no puedo evitar preguntarme qué habría hecho en el pellejo de ese Drazen Erdemovic a quien, si le creemos, repugnó matar a centenares de musulmanes bosnios y aun así lo hizo. No todo el mundo tiene pasta de héroe, menos aún de mártir. Me imagino a Erdemovic tirando su arma al suelo y diciendo: «No dispararé contra esta gente; ponedme con ellos y acabad conmigo, lo prefiero». No, la verdad es que me cuesta imaginar esa escena en la vida real, en la que no hay espectadores que se conmuevan con el gesto noble y lo aplaudan y se vayan después a casa reconfortados y sintiéndose un poco mejores tras haber asistido a semejante prueba de rectitud y sacrificio. Los únicos espectadores de esa función hipotética habrían sido las otras víctimas, que no habrían podido contarlas y los verdugos, que no cuentan nada o si acaso mienten. Uno no hace gestos para sus verdugos. Supongo que en los momentos cruciales de las guerras se piensa sólo en sobrevivir, en pasar de un minuto al siguiente y de éste al que va después, y se debe de pensar, si en realidad se piensa: «Mientras siga vivo, todo puede tener arreglo». El arreglo, por ejemplo, de conmover a unos jueces y conseguir acaso una atenuante, o de que haya gente como yo haciéndose preguntas y escribiendo artículos como éste.

Veamos cuál es la construcción de párrafos del texto, en términos de palabras y enunciados o frases:

Párrafos
1
2
3
4
5

Palabras
85
128
85
191
228

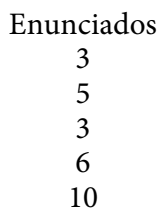

¿Es este un texto desequilibrado o la diferencia cuantitativa entre párrafos tiene que ver con la naturaleza del contenido de cada uno de ellos? Parece que la respuesta más 
adecuada a la pregunta sería la segunda de las hipótesis enunciadas. Así lo confirma el contenido de cada párrafo:

\begin{tabular}{|c|c|}
\hline Párrafos & Contenido \\
\hline 1. Recuerda unos hechos & $\begin{array}{l}\text { Recordatorio } \rightarrow \text { Identificación del personaje y de las circunstan- } \\
\text { cias } \rightarrow \text { Foto del personaje }\end{array}$ \\
\hline $\begin{array}{l}\text { 2. Más detalles sobre el caso } \\
\text { judicial }\end{array}$ & $\begin{array}{l}\text { El personaje se justifica } \rightarrow \text { Justificación: el miedo } \rightarrow \text { Ampliación } \\
\text { de la justificación } \rightarrow \text { Posible condena } \rightarrow \text { Posibles atenuantes }\end{array}$ \\
\hline $\begin{array}{l}\text { 3. La obediencia debida, ¿es } \\
\text { un atenuante? }\end{array}$ & $\begin{array}{l}\text { Reflexión personal sobre los atenuantes } \rightarrow \text { La dificultas de juzgar } \\
\text { la obediencia debida, atenuante en el caso } \rightarrow \text { Definición de la } \\
\text { obediencia debida }\end{array}$ \\
\hline $\begin{array}{l}\text { 4. Reflexiona sobre la gue- } \\
\text { rra }\end{array}$ & $\begin{array}{l}\text { Las guerras son diferentes } \rightarrow \text { Desconocimiento de las guerras en } \\
\text { primera persona } \rightarrow \text { Fuente de una referencia de la guerra } \rightarrow \text { Cita } \\
\text { literal } \rightarrow \text { Ampliación de la cita } \rightarrow \text { Ampliación de la cita }\end{array}$ \\
\hline $\begin{array}{l}\text { 5. Se pregunta qué haría él } \\
\text { en una guerra }\end{array}$ & $\begin{array}{l}\text { Reflexión sobre qué hacer en el caso del soldado } \rightarrow \text { Justificación } \\
\rightarrow \text { Imagina al soldado como héroe } \rightarrow \text { Qué diría el soldado } \rightarrow \\
\text { Vuelta a la realidad } \rightarrow \text { Las víctimas, espectadores de la realidad } \\
\rightarrow \text { No los verdugos } \rightarrow \text { Ansia de sobrevivir } \rightarrow \text { Supervivencia, lo } \\
\text { primero } \rightarrow \text { Incluso justifica o atenúa el comportamiento }\end{array}$ \\
\hline
\end{tabular}

En nuestra opinión, la unidad temática de cada párrafo ha sido garantizada, y la extensión de cada uno de ellos depende no tanto de los conceptos desarrollados como de la intención del autor. Marías decide cuánta información nos quiere dar sobre cada cuestión. En su texto es más importante la sección argumentativa que la narrativa que la sustenta; por ello, los dos últimos párrafos son mucho más extensos que los dos primeros. El párrafo tercero tampoco es especialmente largo porque no le interesa dedicar más tiempo del imprescindible a explicar uno de los conceptos claves: la obediencia debida. Ciertamente, podría haberse detenido en él, pero ha optado por no hacerlo.

\subsection{Dimensión cognitiva}

El párrafo es también una unidad cognitiva que facilita la comprensión del texto por parte del destinatario $\left(\right.$ Chafe, 1980) ${ }^{9}$. Los límites del párrafo responden también a actividades de naturaleza cognitiva como son la interpretación textual y el almacenamiento de la información transmitida, referidas respectivamente a la producción y a la recepción discursiva. Desde la primera, pondremos el acento en el hecho de que la distribu-

\footnotetext{
${ }^{8}$ El signo $\rightarrow$ sólo indica que esos contenidos se acumulan, no el tipo de relación existente entre ellos.

${ }^{9}$ Del mismo modo, Lausberg (1967) defiende que el párrafo cuenta solo con límites psicológicos asociados a la inteligibilidad.
} 
ción en párrafos guía y orienta la comprensión textual en el sentido de que destaca una entre las posibles interpretaciones alternativas. El segundo punto de vista nos permite interpretar el párrafo como instrumento utilizado por el destinatario para la aprehensión del contenido.

El párrafo funciona como herramienta reguladora de la comprensión textual en términos facilitadores o reguladores (Stark, 1988). Y lo hace en dos niveles. Por un lado, destaca la importancia cognitiva de la posición inicial de párrafo: esta facilita el procesamiento (Gernsbarcher y Hargreaves, 1992) y crea expectativas de comprensión en el lector (Green y Noreen, 1974). Por otro lado, el límite del párrafo invita a reflexionar y a valorar la información recibida (Hofmann, 1989). Por ello, en palabras de González Cobas (2008), leemos más despacio a medida que nos acercamos al final de un párrafo.

Queremos detenernos en la primera de las funciones enunciadas. La cuestión ya no es si el párrafo incluye o no una frase tópica: lo relevante es que el enunciado inicial lo ancla temáticamente y genera una línea interpretativa. Con independencia de que ese enunciado inicial se desarrolle o no a lo largo del párrafo. El autor toma una decisión vinculada a su intención textual y que tiene como efecto la orientación de la interpretación. En palabras de Ji (2008), los cambios de párrafo marcan discontinuidades temáticas en el texto y de esa manera facilitan el procesamiento por parte de los lectores. Y la función que estamos definiendo se observa con independencia de la naturaleza tipológica del texto del que se trate. Veremos para ello tres ejemplos:

En el primero se le pide a un estudiante que realice una descripción de su vivienda habitual en 250 palabras aproximadamente. Este es el resultado:

EN UN BARRIO DE LA CIUDAD DE A CORUÑA, A UNOS DIEZ MINUTOS DEL CENTRO DE LA CIUDAD, SE ENCUENTRA UN EDIFICIO DE UNOS DOS TRES AÑOS DE ANTIGÜEDAD. De color beige y ventanales blancos destaca entre las demás fachadas por su estilo propio del centro histórico. Tiene tan solo siete pisos, de los cuales solo los de la parte de delante tienen vistas a la Ría de A Coruña y a playas como Santa Cristina, Mera o Bastiagueiro. Además, los pequeños balcones que dan a la calle está llenos de geranios y plantas que ponen las vecinas para decorar y dar un poco más de alegría.

MI CASA SE ENCUENTRA EN LA SÉPTIMA PLANTA Y LA DISTRIBUCIÓN ES MUY SENCILLA. Al entrar por la puerta encuentras la oficina con la librería, y a mano izquierda das al gran pasillo al cual dan dos habitaciones, una de mi hermana y otra mía. Al fondo está la de mis padres que tiene vistas al mar además de un baño. La siguiente es el salón comedor, desde el que también ves la Ría por sus grandes ventanales. En frente está el otro baño, y ya lo último la siempre inmaculada blanca cocina.

EN MEDIO DE LA CASA SE ENCUENTRA MI HABITACIÓN QUE DESTACA POR EL FUERTE COLOR VERDE MANZANA DE LAS PAREDES, LAS CUALES ESTÁN DECORADAS POR TRES CUADROS QUE 
ME PINTÓ UNA AMIGA ESTAdOUNIDENSE. Pegada a una de ellas está mi cama con su edredón a rayas de colores, y al lado una estantería a rebosar de libros. En frente a la cama está la ventana que da a un patio interior y justo debajo está mi mesa de escritorio, siempre llena de papeles y apuntes. El lado opuesto está cubierto por el enorme armario empotrado de la misma madera que el resto de muebles que decoran mi habitación y que están llenos de discos, peluches y velas. El suelo está cubierto por una alfombra de color azul que hace juego con las cortinas, cojines y lámpara. Y por último, la puerta, que está llena de fotos de mis amigos y familia, lo que le da un toque más personal.

El primer enunciado, que hemos destacado en letras versalitas, no es necesariamente una frase tópica (solo la segunda lo sería) pero condiciona al lector en términos interpretativos. Este presupone que en el primer párrafo se va a indicar la ubicación de la casa en la ciudad; en el segundo, la distribución de la vivienda; y en el tercero, las características de la habitación del autor o autora. Lo esencial ahora es que la frase con la que comienza el párrafo no lo condiciona formal ni conceptualmente sino que regula el proceso de interpretación del destinatario.

Lo mismo se observa en un texto narrativo. Un estudiante desarrolla una historia en 300 palabras aproximadamente:

EL CONDUCTOR BAJÓ DEL COCHE. Estaba fuera de sí, tanto, que ni se daba cuenta de que Fernando estaba inconsciente por el golpe recibido. Caminaba hacia el joven sin dejar increparle. Cuando llegó hasta él, comprendió la grave situación en que se encontraba el chico. Rápidamente, llamó a una ambulancia, que apareció en pocos minutos acompañada de un coche de policía. Mientras los médicos atendían al muchacho, el propietario del vehículo contó a los agentes lo sucedido. Éstos le dijeron que tenían que detenerle. El conductor no opuso resistencia. Mientras tanto, Fernando se dirigía al hospital con pronóstico grave.

CUANDO LLEGÓ, FUE TRASLADADO AL QUIRÓFANO. Le realizaron una transfusión y le dieron varios puntos de sutura. Despertó a la mañana siguiente. No sabía ni donde estaba, ni que le había pasado. Pero pronto apareció una enfermera que le explicó lo que había ocurrido.

UNA SEMANA DESPUÉS ABANDONÓ EL HOSPITAL. No había avisado a sus padres para no preocuparles. Además, su estancia en el hospital le había hecho reflexionar sobre la decisión de abandonar su pueblo, por lo que se dirigía al mismo para hablar con su familia.

TRAS EXPLICAR A SUS PADRES LO QUE LE HABÍA OCURRIDO, SE FUE A HABLAR A SOLAS CON SU PADRE. Cogió la vieja bufanda y se la devolvió. Le dijo que ya no la necesitaría, pues había decidido quedarse en el pueblo a ayudarles con el trabajo en el campo, ya que la 
vida de la gran ciudad no era para él. Padre e hijo se fundieron en un abrazo y junto a su madre, regresaron a casa.

Ahora es aún más evidente que la primera frase de cada párrafo carece de naturaleza tópica. El autor las usa para destacar los que considera hitos más importantes en el devenir de los acontecimientos narrados, y parcela la información sobre ellos. De hecho, no suponen una suerte de resumen textual (cosa que sucedería en caso de tratarse de frases tópicas) sino más bien una focalización sobre los datos interpretados por el autor como más relevantes.

Veamos un último ejemplo: se trata de un texto de opinión acerca de si se debe permitir una mujer someterse a una fecundación artificial a los 67 años:

RECIENTEMENTE SE HA HECHO PÚBLICA LA NOTICIA DE LA MUJER QUE, A SUS 67 AÑOS, SE HA CONVERTIDO OFICIALMENTE EN LA MADRE MÁS VIEJA DEL MUNDO. El alumbramiento de dos mellizos a estas alturas de la vida de la señora, le han hecho merecedora del título. Pero otro asunto que llama la atención es lo que tuvo que hacer para conseguir aquello que, según ha declarado, siempre había ansiado.

TENIENDO EN CUENTA LA AUSENCIA DE PAREJA Y LOS IMPEDIMENTOS BIOLÓGICOS OBVIOS, LA ÚNICA SALIDA ERA LA FECUNDACIÓN IN VITRO. Para ello, viajó a Los Ángeles donde está permitido sólo hasta los 55 años. Pues bien, a pesar de que la mayoría de los titulares afirman que la señora mintió sobre su edad, ella simplemente se defiende aclarando que nadie le preguntó o se preocupó de comprobar. Cabe resaltar posiblemente lo poco que parece importarle a la clínica en cuestión si se cumplen o no los requisitos, mientras una pueda pagar el tratamiento. Otra cosa que personalmente me alarma es el hecho de que haya vendido su casa para obtener los 45.000 euros necesarios para pagarlo. Yo me pregunto cuál es el plan de esta mujer ahora que tiene dos hijos. Sólo ella sabe los ahorros que puede tener o su situación en general, pero en cualquier caso, lo que se sabe es que la mujer no tiene casa, se ha gastado lo que para muchas familias es toda una fortuna para tener dos niños, los cuales, derivado de todo lo anterior no se sabe donde serán criados.

DESDE LUEGO, NO ES CUESTIONABLE QUE UNA MUJER TENGA EL DESEO DE SER MADRE NI, MUCHO MENOS, QUE DEFIENDA SU DERECHO A SERLO. Sin embargo, éste se vuelve una controversia cuando se trata de desafiar a la Naturaleza que, salvo malas jugadas y como dice el dicho, es sabia. Esto es, si llega un momento en la vida de las féminas en el que estas dejan de tener posibilidad de procrear, es debido a evitar una serie de riesgos para la madre y el bebé. Asimismo, aquellas que den a luz a sus hijos a una mayor edad, tendrán menos tiempo ya no de disfrutarlos, pero de educarles y criarles hasta que estos alcancen una madurez. Lo cuestionable son, en realidad, los métodos utilizados. ¿Pero quién puede culpar a una persona de saltarse las normas para conseguir lo que más ansía si, de hecho, quien debería hacerlo no se aseguró de que las cumpliera? 
Tres son los conceptos relevantes en términos informativos y de acuerdo con la distribución de párrafos propuesta por el autor: la edad de la mujer, que la convierte en la madre más vieja del mundo; la realización para ello de una fecundación in vitro; y la incuestionabilidad del derecho de una mujer a ser madre. Especialmente llamativo resulta el tercer párrafo: el autor pone en primer el derecho universal de la mujer a ser madre por encima de cualquier otra consideración en un tema esencialmente controvertido: la posición inicial del enunciado condiciona de modo evidente la interpretación global del párrafo.

Desde la segunda dimensión cognitiva apuntada al principio de este epígrafe, descubrimos una función del párrafo asociada al modo en el que almacenamos la información textual. Se convierte entonces en base de la creación de esquemas cognitivos destinados a regular la comprensión textual. En opinión de Haberlandt, Brian y Sandson (1980), cada esquema coincide con un párrafo y cambia con cada uno nuevo que se construye. Según González Cobas (2008), el cambio de párrafo supone un cambio de esquema cognitivo. En la misma dirección, Pérez Juliá (1998) asevera que el párrafo genera una imagen esquemática utilizada en el proceso de almacenamiento de la información.

Cada párrafo se convierte en un segmento coherente y asimilable (De la Fuente, 2007), en una unidad informativa autónoma que facilita ir hacia delante o hacia detrás para alcanzar una correcta comprensión del texto (Stark, 1988). Los límites de párrafo indican al lector que debe procesar la información contenida en la memoria a corto plazo. Todo ello lo convierte en una auténtica unidad de procesamiento informativo: Hofmann (1989) dedica su esfuerzo a reunir pruebas que demuestran su función como herramienta fundamental en la aprehensión cognitiva. Entre ellas indica que el párrafo muy extenso tiende a confundir al lector y por ello no es extraño que, aun cuando la estructura lógica de los argumentos suele coincidir con la división en párrafos, un concepto complejo puede exigir varios de ellos; por otro lado, la acumulación de párrafos cortos también resulta molesta porque dispersa demasiado la información y la representa de modo menos integrado ${ }^{10}$.

Igualmente oportunas al respecto son las propuestas de Pérez Juliá (1998). El párrafo es una unidad semántica construida en estrecha relación con la memoria. Es una auténtica unidad perceptiva cuyo aspecto cuantitativo (esto es, su extensión) afecta directa-

\footnotetext{
${ }^{10}$ Muy interesante su apunte acerca de la literatura infantil: los libros destinados a niños menores de 5 años se construyen con párrafos muy cortos para facilitar el procesamiento.
} 
mente al nivel de persistencia en la memoria ${ }^{11}$. Si todo esto es cierto, funciona como herramienta de parcelación del contenido textual y facilita la lectura al incluir momentos de ruptura destinados a evitar la fatiga (Stark, 1988). Por todo ello, un párrafo no puede ser ilimitado. Mejor dicho, puede serlo, pero sería inútil. Porque transmitiría un concepto tan complejo que acabaría por convertirse en incomprensible. A fin de cuentas, la razón por la que rechazamos un párrafo demasiado extenso suele ser doble: o bien porque el sentido contenido es heterogéneo y, por ello, susceptible de ser dividido; o bien porque siendo homogéneo, resulta incomprensible.

Es lo que sucede en el ejemplo siguiente. Pese a la extensión del texto, parece oportuno transcribirlo de manera completa ${ }^{12}$. Estamos ante la friolera de 1161 palabras ininterrumpidas. El párrafo sustituye al texto:

\section{EL PARTENÓN}

Nos hemos acostumbrado a ver el Partenón cara a cara desde el marco de los Propíleos, recortada su silueta en medio de la Acrópolis, allí solo, como si estuviera esperándonos. Una visión pictórica y romántica, pero impensable en la Antigüedad. No existían por entonces los encuadres monumentales, ni las perspectivas arquitectónicas, ni los marcos incomparables, sino que cada monumento era una unidad plástica, ella en sí misma. Hay que esperar al Helenismo para que cambie el criterio, por eso en plena época clásica el espectador no se extrañaba, tras haber atravesado los Propíleos, de encontrarse el Partenón tapado por monumentos vecinos y rodeado de estatuas, ofrendas, exvotos... Habia que ir a buscarlo, llegar hasta él, y la proximidad impedía el efecto en perspectiva. Nos hemos acostumbrado también a identificar el Partenón con una ruina discontinua, sin el remate de la techumbre y carente de la policromía. Pensándolo bien, es asombroso que quede lo que queda, después de haber sido utilizado como iglesia bizantina, mezquita, polvorín y haber sufrido explosiones, incendios, terremotos y expolios, sin olvidar la erosión de siglos a la intemperie. Su fama permaneció intacta siempre, o mejor, acrecentada con el tiempo, razón de que se hayan acumulado noticias e información sobre él. Hoy día es mucho lo que se sabe del Partenón y; sin embargo, la investigación arqueológica no cesa en su avidez de más y mejores conocimientos. Algunos de los más recientes nos han devuelto con toda fiabilidad la imagen prístina, real y concreta de la obra más emblemática de la arquitectura griega. La cronología del Partenón la tenemos asegurada por inscripciones que fijan el comienzo de las obras en el curso del año 448-447 y el final en 438, lapso de tiempo brevísimo, cuando se piensa en

\footnotetext{
${ }^{11}$ Desde esta postura, Pérez Juliá propone una interesante clasificación de párrafos según su función cognitiva.

${ }^{12}$ Dirección del sitio web: http://www.artehistoria.com/.
} 
la magnitud de la obra. Toda ella fue realizada en mármol pentélico. Como arquitectos mencionan las fuentes a Iktinos, Kallikrates y Karpion, nombre este último que no volvemos a encontrar. Las ideas básicas del proyecto las aporta Iktinos, un arquitecto genial que escribió un libro, desgraciadamente perdido, sobre las teorías desarrolladas en la construcción del Partenón. Su idea de lo que es un templo dórico y de cómo se modela el espacio se tiene al comparar el Partenón con el templo de Zeus en Olimpia y con el llamado Prepartenón, es decir, el templo dórico hexástilo que estaba en construcción en 480, cuando los persas arrasaron la Acrópolis, y sobre cuyos fundamentos se alzó el Partenón. El parangón demuestra que éste es más monumental, más cerrado y más compacto, aunque en sus miembros se extrema la finura y la delicadeza. La planta es la de un templo octástilo, dístilo y anfipróstilo, cuyas columnas se encuentran más próximas entre sí y la cella, con la natural repercusión en los espacios interiores, como enseguida veremos. Respecto al canon dórico de Olimpia se observa que la ampliación de la perístasis $(8 \times 17)$ y la ampliación considerable de la cella van en detrimento de la anchura del pasillo existente entre ambas y denotan un nuevo sentido del espacio, pues el conjunto resulta más grandioso y unitario. De hecho, la amplitud y la espaciosidad del Partenón se perciben desde fuera y desde dentro, dada la perfecta conjunción e interdependencia de exterior e interior. Por su arte, el nuevo sentido del espacio, que modifica sensiblemente las proporciones de la cella, es una novedad importantísima, cuya causa primordial es la colosalidad de la estatua de Atenea Partenos, que tiene absorto a Fidias durante el proceso constructivo. El basamento de la estatua, que se conserva in situ, es monumental; exigía enorme anchura, de donde la necesidad de ampliar la cella. Se trata, pues, de una solicitud de Fidias a Iktinos, ante la necesidad de un escenario adecuado para el coloso de $11 \mathrm{~m}$ que fue la Partenos. Por idéntico motivo, en vez de una cella de tres naves con doble columnata paralela, las columnas se curvan en forma de U por la parte posterior de la nave central, como si de un nicho, para ubicar la estatua de Atenea, se tratara. Fue una solución revolucionaria, cuya influencia se dejó sentir inmediatamente. Frente a estas novedades inesperadas hay en el Partenón peculiaridades que no son originalidad del proyecto arquitectónico, sino consecuencia o adaptación a tradiciones ancestrales. Así, por ejemplo, la división de la cella en dos espacios desiguales y la introducción de rasgos jónicos en un templo dórico -el friso que recorre los muros de la cella y las cuatro columnas jónicas de la menor de las dos estancias en que queda dividida la cella- deben considerarse rasgos heredados del Prepartenón e incluso del llamado Templo Dörpfeld de época pisistrátida. Hay en el Partenón refinamientos casi inaprehensibles, pero de extraordinaria eficacia a la hora de darle ese carácter vital de músculo activo tantas veces señalado. Son las llamadas correcciones ópticas, que en sí mismas no son novedad, aunque la tiene en grado sumo la manera de interpretarlas o hacerlas valer. Se persigue con ellas una estudiada contraposición en los miembros del orden arquitectónico según la función ejercida, a partir de la que se obtiene una perfecta compensación de efectos visuales; algo así como la versión arqui- 
tectónica del contraposto escultórico, dice Gruben. Como muy sobresalientes hay que citar el mayor grosor de las columnas laterales respecto al de las centrales, para neutralizar la impresión de adelgazamiento provocada por la intensidad de la luz en las esquinas, así como la inclinación hacia dentro de todas las columnas. En segundo lugar, la contracción de las metopas propagada desde el centro; es decir, la anchura de las metopas disminuye progresiva e imperceptiblemente a partir del centro, de manera que se evita el cambio brusco de dimensiones, más anchas sólo en las dos últimas metopas de cada lado. Por último y principalísimo, la curvatura de todos los elementos horizontales, desde las gradas del estilobato al entablamento. A consecuencia de la curvatura y de las líneas de fuga, siempre verticales, los bloques de mármol no son rectangulares sino trapezoidales; cada uno de ellos hubo de ser cortado y tallado individualmente, detalle que merece ser tenido en cuenta para aquilatar la dificultad y calidad del trabajo. El ensamblaje tan cuidado como armonioso de todos estos pormenores es lo que hace distinto al Partenón. Un par de ideas sobre la policromía. Lo que realmente manda, a efectos cromáticos, es la calidad inigualable del mármol pentélico, cuya transparencia y blancura definen el núcleo de la obra. Triglifos, mútulos, regulae iban pintados de azul, como es frecuente en los elementos verticales, mientras la taenia o moldura lisa, la banda que corre por debajo de los triglifos y el listel superpuesto a ellos iban decorados con un meandro datado sobre fondo rojo, como si fuera el motivo tejido en una cinta o en un galón. El acasetonado del techo quedaba enmarcado por motivos vegetales, ocupado el centro por una palmeta exquisitamente dibujada sobre fondo azul. Policromada iba lógicamente la decoración escultórica: metopas del friso dórico, friso jónico y frontones.

El texto podría (más aún, debería) estar segmentado en nueve párrafos, que se corresponderían con otras tantas unidades de sentido. Podemos esquematizarlas de este modo:

\begin{tabular}{|c|c|c|}
\hline PÁRRAFOS & PALABRAS & CONTENIDO \\
\hline 1 & 123 & Imagen tradicional de Partenón desde los Propileos \\
\hline 2 & 81 & Imagen tradicional del Partenón como ruina \\
\hline 3 & 92 & La investigación sobre el Partenón no cesa \\
\hline 4 & 111 & Los arquitectos del Partenón \\
\hline 5 & 133 & Características arquitectónicas \\
\hline 6 & 145 & El nuevo sentido del espacio condicionado por la estatua de Atenea \\
\hline 7 & 88 & Peculiaridades consecuencia de adaptarse a la tradición \\
\hline 8 & 266 & Refinamientos apenas aprehensibles \\
\hline 9 & 122 & La policromía \\
\hline
\end{tabular}

De ese modo se facilitaría la percepción textual y se evitaría el colapso en el procesamiento informativo. 


\section{Algunas pruebas}

Para confirmar o desmentir los conceptos desarrollados en los epígrafes anteriores, hemos realizado un análisis que, sin aportar datos definitivos, sí apunta tendencias muy reveladoras. Para ello hemos partido de un corpus que responde a las siguientes características: la muestra de textos fue redactada por estudiantes matriculados en el primer curso de la Licenciatura en Traducción e Interpretación impartida en la Universidad de Salamanca; han tenido que superar una prueba de acceso en la que se ha evaluado su dominio escrito de la lengua española, por lo que han sufrido una nivelación de mínimos. Todos los estudiantes redactan dos escritos. El primero, antes de recibir instrucción general en expresión escrita y específica sobre el párrafo (mes de noviembre del curso académico) y en una asignatura diferente de aquella en la que reciben tal formación. El segundo texto se realiza después de la instrucción (mes de mayo del curso académico) y en el contexto de la materia en la que se les instruye sobre redacción en español.

Los dos textos son de naturaleza expositiva. El primero es un comentario crítico de 500 palabras aproximadamente sobre un artículo científico. Al no haber recibido formación específica, aplican un saber intuitivo o bien resultado de su formación preuniversitaria; este trabajo aparece codificado como TM. El segundo es un trabajo de 1.800/2.000 palabras en el que se establece una comparación entre una novela y una película de cine; nos referimos a él como TV. Los datos relativos a ambos textos son lo siguientes;

\begin{tabular}{|c|cc|}
\hline & TM & TV \\
\hline Textos & 59 & 74 \\
Palabras & 35.016 & 134.326 \\
Párrafos & 392 & 1.126 \\
Enunciados & 1.570 & 6.039 \\
\hline
\end{tabular}

Para el análisis de los datos partimos de distintas hipótesis desarrolladas desde los conceptos expuestos a lo largo de la primera parte de este trabajo. A ellas añadimos una nueva variable: hemos de tamizar los resultados desde la perspectiva de si los usuarios han recibido o no instrucción específica acerca de la construcción de párrafos.

En primer término, si un párrafo es una unidad informativa compleja, es verosímil pensar que los usuarios apenas habrán construido párrafos de un solo enunciado. Además, suponemos que el número de enunciados combinados es directamente proporcional a la complejidad temática del párrafo. Por ello habrá algún tipo de límite para el número de enunciados que se combinan en un párrafo. Por otra parte, desde una perspectiva retórica habrá que evaluar si los usuarios tienden a utilizar un tipo de párrafo 
homogéneo en longitud y complejidad temática o si, por el contrario, no dan relevancia a esta cuestión.

En segundo lugar, si hay conciencia en los usuarios de la dimensión visual de los párrafos, cabe pensar que habrá una tendencia a dividir el texto en un número de párrafos similar si aquel tiene una extensión también parecida. Asimismo, habrá que comprobar si hay alguna regularidad relativa a la construcción de párrafos de longitud similar.

En tercer lugar, si entendemos el párrafo como unidad de procesamiento, tendremos que analizar la longitud de párrafos en términos de número de palabras para observar si existe algún tipo de tendencia global y si hay limitaciones por arriba y por abajo: partimos de la asunción de que el párrafo largo genera expectativas de mayor densidad, mientras que el corto lo hace de ligereza conceptual. También debemos considerar si la longitud global del texto tiene efectos en la longitud parcial de los párrafos insertos; en otras palabras: si un texto informativamente más prolijo distribuye su contenido en unidades de construcción igualmente más complejas.

\subsection{Sobre la complejidad temática}

En TM se detecta la siguiente distribución de párrafos según el número de enunciados combinados: el rango establecido está entre una y diecinueve unidades informativas mínimas. La cuantificación está realizada en términos porcentuales:

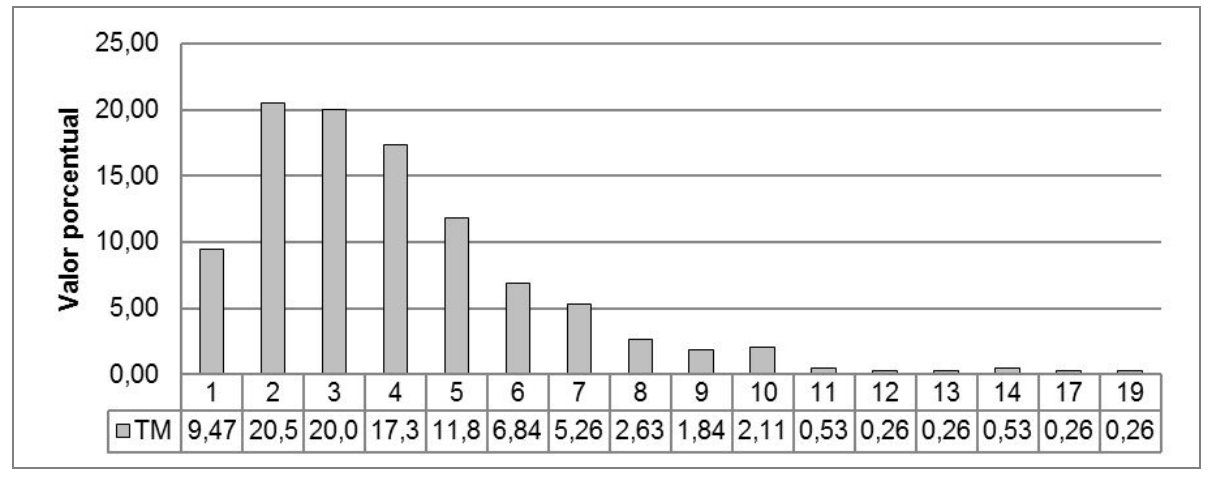

Algo más del 90,5\% de los párrafos se componen de dos o más enunciados; la mayoría de ellos están distribuidos entre dos y cuatro. En cambio, párrafos de nueve o más solo suponen el $6,05 \%$ de la muestra. Se confirma, pues, que los autores tienen conciencia del párrafo como unidad informativa compleja porque se tienden a combinar dos o más enunciados. Sin embargo, realizan una escasa planificación del 
texto, lo que les lleva a construir párrafos bastante reducidos: la franja entre dos y cuatro reúne un $57,8 \%$ de la muestra, y dentro de ella los más frecuentes son los de dos, luego los de tres y finalmente los de cuatro. Al mismo tiempo, se escapa de los párrafos de excesiva complejidad temática: es testimonial la aparición de párrafos de más de diez enunciados (2\%). En conclusión, podemos afirmar que la complejidad temática se respeta pero se observa que es cualitativamente limitada.

El 9,47\% de los párrafos escapan a esta percepción de unidad informativa compleja. Debemos destacar que casi un 30\% tiene una función conclusiva y cierra el texto, del que es el último párrafo. Algunos ejemplos:

En resumen, opino que Pinker tiene razón al negar el determinismo lingüístico y además creo que su exposición está muy bien presentada y argumentada.

En conclusión, actualmente la teoría de Sapir y Whorf ya ha sido superada por otras más avanzadas, gracias al progreso científico, y ha quedado en evidencia su falta de lógica.

Para concluir, el lenguaje no determina el pensamiento sino que es el código mediante el cual lo reproducimos a nuestra voluntad o, al menos, eso intentamos.

Como conclusión, se puede decir que sin pensamiento no habría lenguaje, ya que si las cosas no se pensarán no tendrían ningún significado.

En TV, por su parte, la distribución es esta:

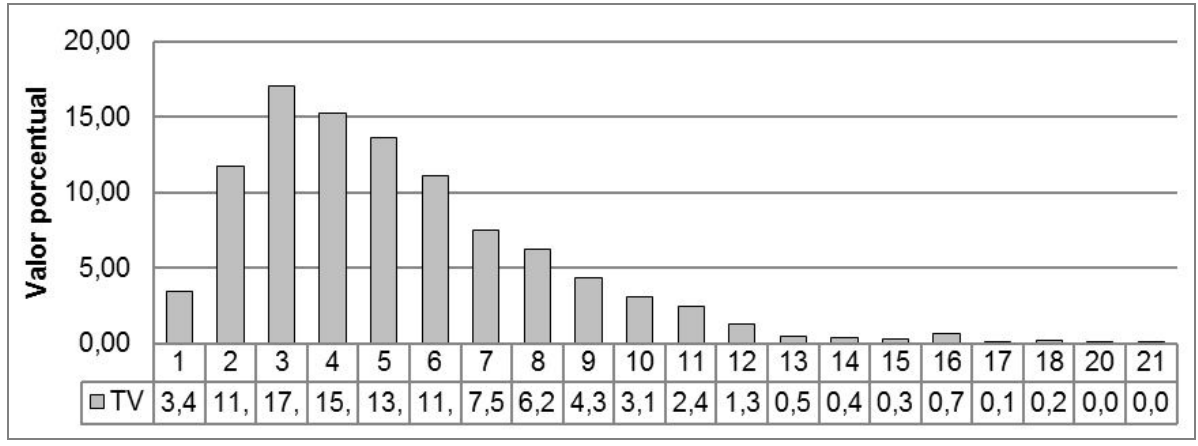

El 95,5\% de los párrafos se construye con dos o más enunciados, de donde se deduce que la instrucción en expresión escrita consolida la percepción del párrafo como unidad temáticamente compleja. Además, se observa que esta ha aumentado en términos cualitativos: los más frecuentes son los párrafos de tres enunciados, luego los de cuatro, a continuación los de cinco y finalmente los de dos, que eran los más repetidos en TM. Por último, la franja de mayor frecuencia está entre tres y seis enunciados: acumula el $57 \%$ de los ejemplos. 
Por otra parte, el límite de la complejidad ha aumentado en comparación con el primer texto estudiado. Así, se observa cierta frecuencia en párrafos de hasta doce enunciados (frente a diez en el caso de TM): de trece o más, suponen el 2,6\%. De todo ello se colige que la conciencia del párrafo como unidad informativa compleja se ha consolidado como resultado de la instrucción específica.

Podemos terminar comparando los resultados en los dos textos:

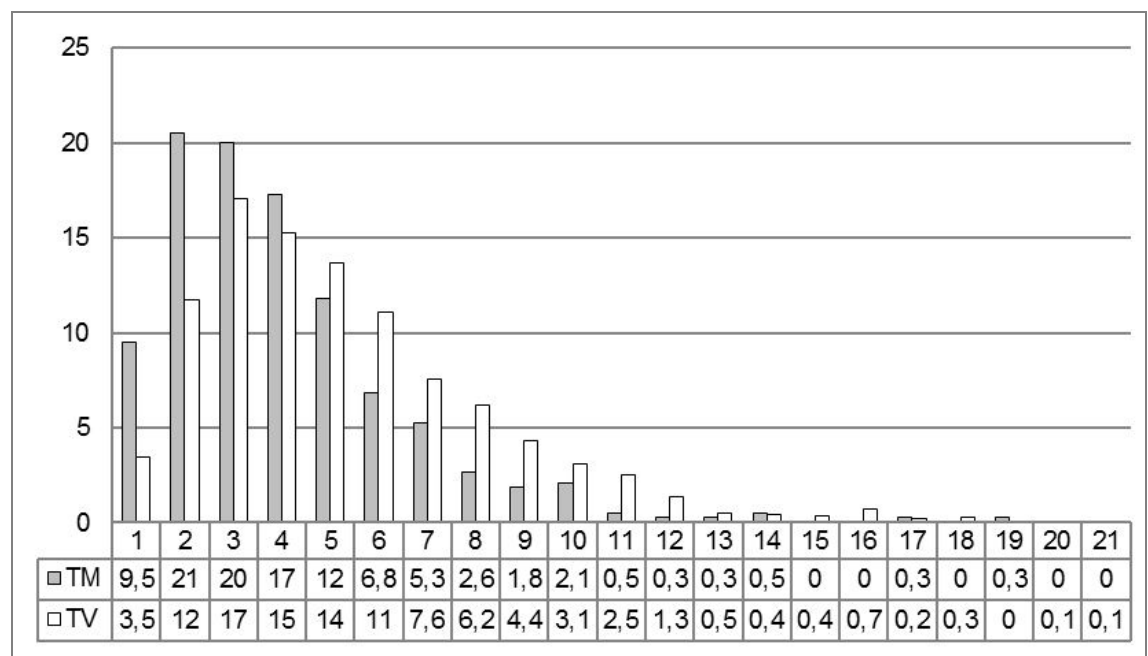

Es evidente cómo en ambos casos, pero más en TV, se renuncia al párrafo de un enunciado. Asimismo, también es de destacar que la complejidad temática está más desarrollada en TV. De hecho, en este caso, la construcción porcentualmente habitual del párrafo es mucho más variada: de tres a seis enunciados; en cambio, en TM se observa una decidida preferencia por opciones de dos, tres o cuatro enunciados. La complejidad temática es más evidente, cualitativa y cuantitativamente, en los párrafos construidos por usuarios que han disfrutado de una instrucción específica.

\subsection{Sobre la imagen visual del párrafo}

Si la imagen visual del párrafo es importante en el proceso de construcción textual, debería detectarse una cierta estabilidad entre el cociente entre el número de palabras de un texto y el número de párrafos construido. Desde este cálculo podríamos deducir una suerte de extensión prototípica.

Veamos qué sucede en el caso de TM. Para ello, hemos agrupado los cocientes por franjas de treinta palabras empezando a contar desde el menor detectado $(46,36)$. 
Treinta palabras equivalen aproximadamente a dos líneas de texto impreso en un formato estándar y reconocible (Times New Roman 12) y, por tanto, parece razonable utilizar esta cantidad a la hora de evaluar los márgenes de uniformidad visual reconocibles por el lector:

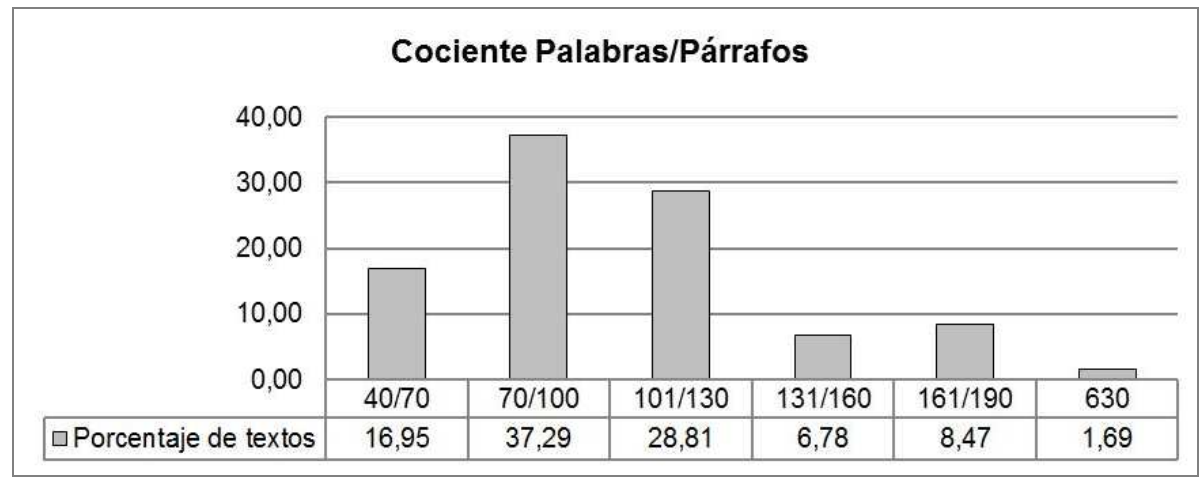

La mayor uniformidad se observa entre setenta y ciento treinta palabras, y afecta al 66\% de los párrafos. No obstante, no es una tendencia muy estable puesto que afecta a un márgen de sesenta palabras. En todo caso, sí parece que indica algún tipo de conciencia acerca de la dimensión visual del párrafo el hecho de que se escapa de los párrafos muy cortos o muy largos: los ejemplos con un cociente inferior a setenta palabras o superior a ciento treinta y una se limitan a un $17 \%$ en uno y otro caso. Esta es, sin duda la cuestión más relevante: no podemos tanto proponer un tamaño prototípico como indicar tendencias acerca de lo que los usuarios evitan en términos visuales.

Debemos comprobar a continuación si estas tendencias se confirman en el caso de TV. Usamos las mismas franjas:

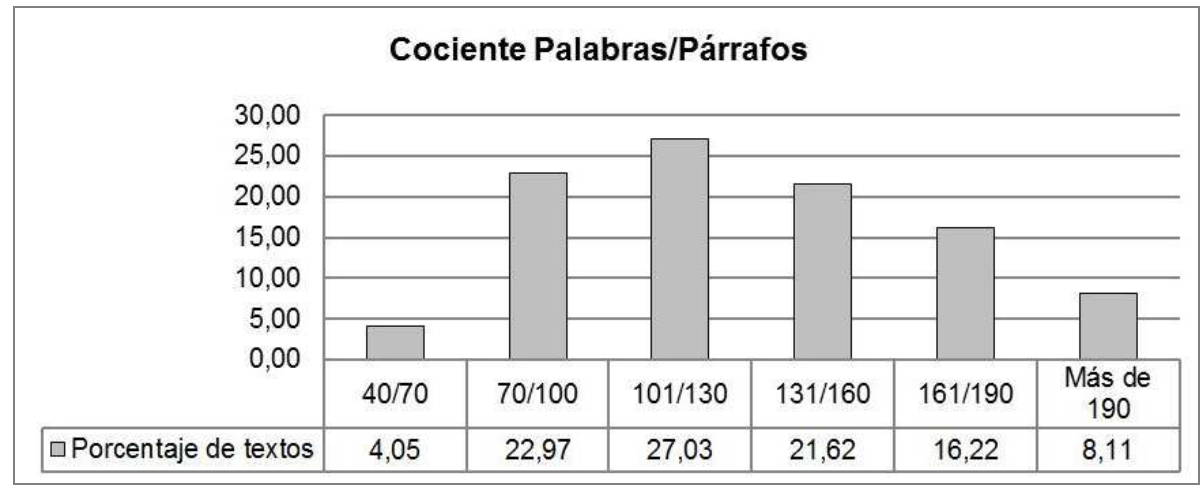


Se produce una reducción evidente de la importancia eventualmente atribuida a la percepción visual. Los párrafos se distribuyen de manera casi idéntica en las tres franjas centrales. Por otro lado, se desprecia la construcción de párrafos visualmente muy pequeños (4\%); enfrente, aumenta la tendencia a usar unidades más largas: por encima de ciento sesenta hay casi un $25 \%$ de ejemplos. En ello bien puede tener que ver el hecho de que el encargo de texto es mayor: dos mil palabras de TV frente a las quinientas de TM. Resulta muy llamativo observar los datos de TM y TV de forma combinada:

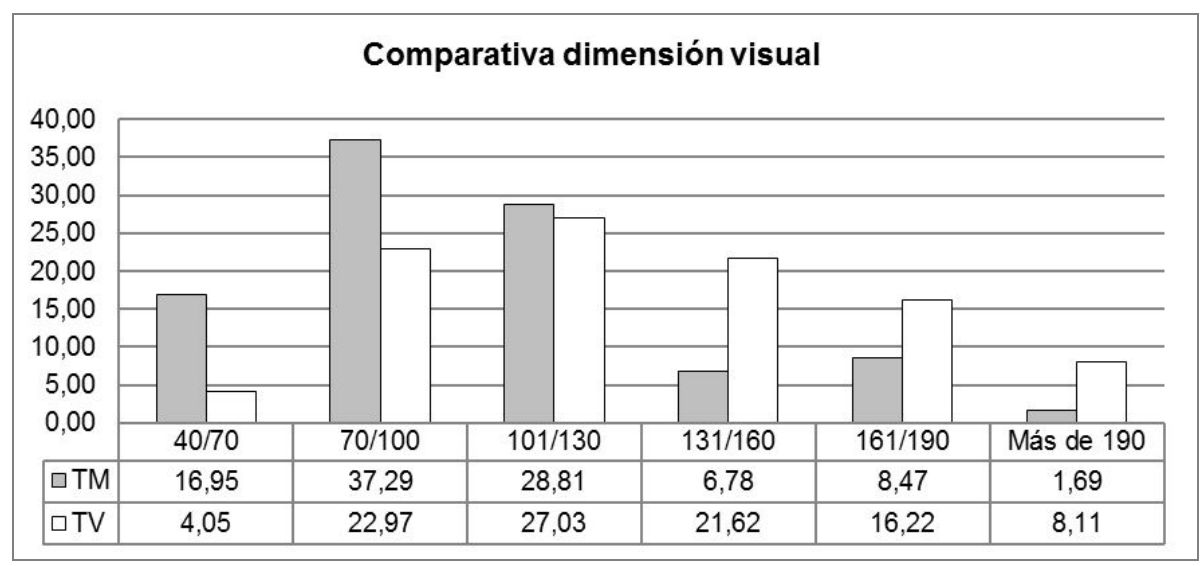

La identificación de la unidad visual del párrafo parece reducirse en la medida en que aumenta la instrucción. Y con ella también disminuye de forma drástica la construcción de párrafos visualmente cortos quizá porque aportan una imagen excesivamente fragmentada del texto. El escritor más experto construye los párrafos condicionado por la estrategia de distribución informativa que ha asumido, y no está tan preocupado por si la página presenta una imagen externa más o menos homogénea.

En segundo término, a la hora de valorar la importancia de la dimensión visual del párrafo podemos aprovecharnos de otro tipo de información derivada de la hipótesis siguiente: si la variable es de relevancia, se tendería a construir más o menos la misma cantidad de párrafos para una misma extensión textual. En el caso de TM vamos a reducir la muestra de los cincuenta textos de partida a cuarenta que tienen una extensión entre cuatrocientas setenta y cinco y quinientas setenta y cinco palabras: la media de palabras por párrafo en este grupo de textos es de 94,2; por ello cabría plantear la hipótesis de que entre el mayor y el menor podría haber una diferencia máxima de un párrafo. Los datos revelan lo siguiente: 


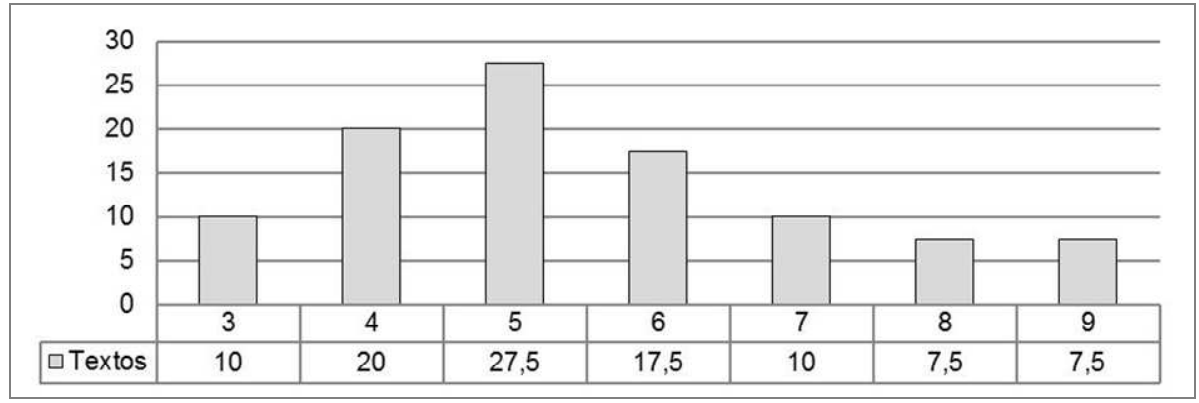

El $65 \%$ de los textos se construyen en un rango de cuatro a seis párrafos. Es, pues, una tendencia, pero sobre la base de unas opciones de construcción lo suficientemente amplia como para deducir una incidencia fundamental en la construcción de los textos.

Por otro lado, para recabar los datos correspondientes a TV hemos reducido la muestra a los cuarenta y seis textos entre mil setecientas cincuenta y mil novecientas palabras. En ellos la media por párrafo es de 121 palabras, por lo que la máxima diferencia posible entre el más corto y el más largo sería de un párrafo. Los resultados, obviamente, no son comparables con los de TM porque la extensión de los textos es tres veces mayor. En todo caso se observa cómo esa cierta tendencia a la uniformidad desaparece por completo:

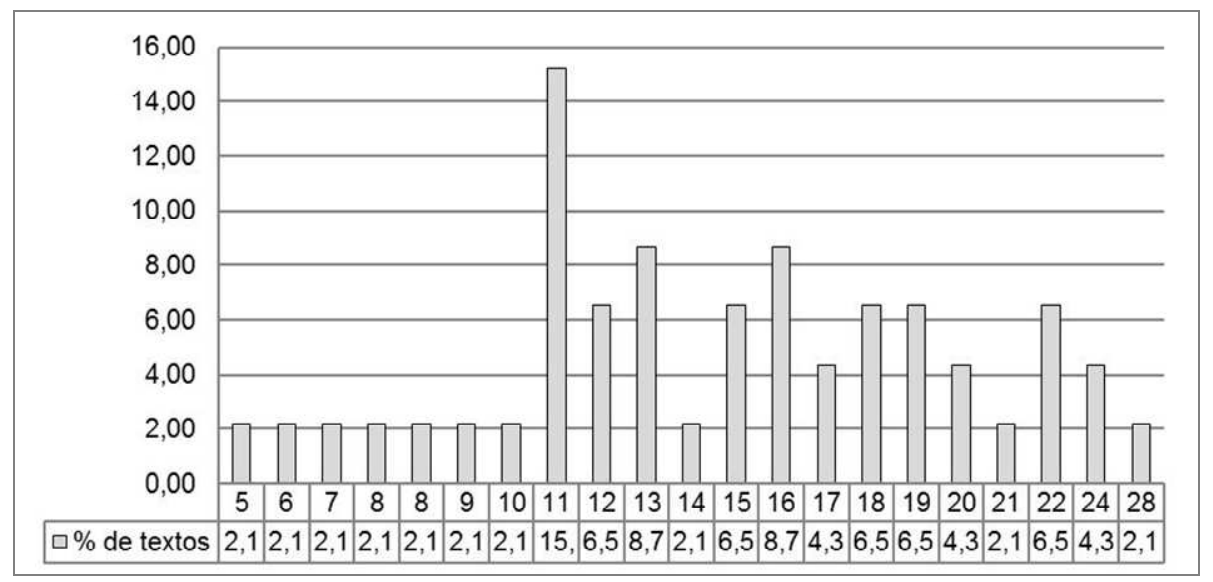

Solamente destaca del grupo de textos que combinan entre once y trece párrafos, pero apenas cubren el $31 \%$ de los textos. La variedad es muy destacable: sirva como ejemplo que el porcentaje de textos desde cinco hasta diez párrafos es el mismo. 
Por todo lo dicho, parece sensato pensar que la variable visual tiene menos importancia que la temática en la contrucción de párrafos. Además, esa relevancia disminuye en la medida en que aumenta la formación de los usuarios en expresión escrita, ya que se pliega a las estrategias de construcción informativa. De hecho, esa reducción se ha de poner necesariamente en correlación con un aumento de la dimensión retórica: la pérdida de uniformidad en la construcción de párrafos se asocia, sin duda, a una distribución intencional de la información.

\subsection{Sobre la dimensión cognitiva del párrafo}

Evaluamos la complejidad cognitiva del párrafo tomando como variable fundamental para el análisis el número de palabras que incluye. Vamos a interpretar los párrafos de los textos con los que trabajamos en franjas de cincuenta palabras. Interesa observar de manera comparada los datos que emanan de los dos textos. Los presentamos de modo porcentual:

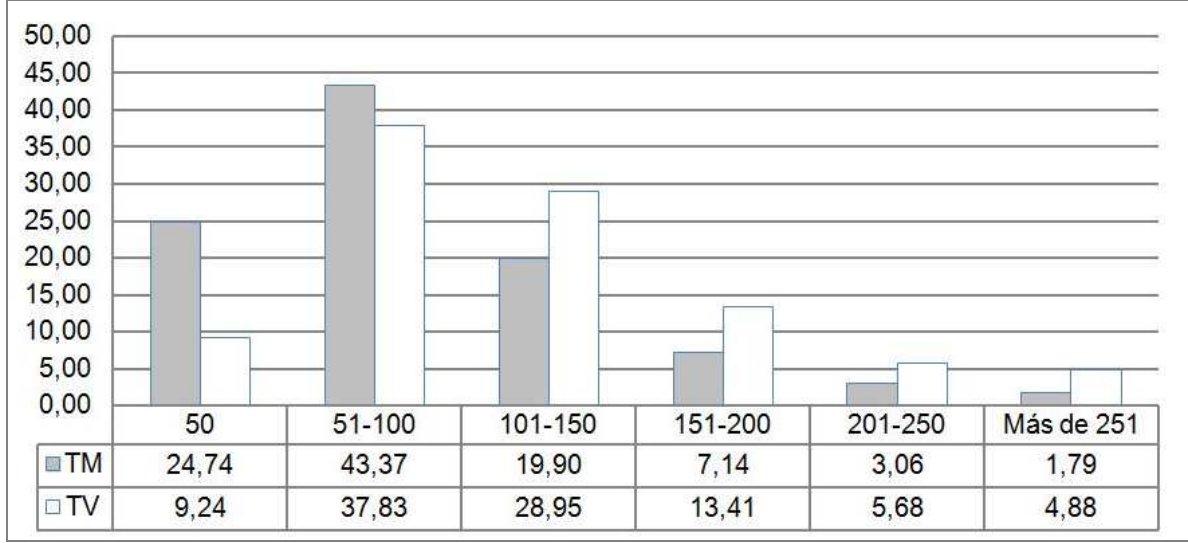

En los dos casos se observa que la importancia de la construcción de los párrafos en el procesamiento informativo tiene como resultado que se evite proponer unidades superiores a las doscientas palabras: apenas se supera el 10\% de los ejemplos en el caso de TV, y se limita al 4,8\% en TM. Cuando los estudiantes han completado la instrucción se observa que, de la misma manera que se escapa del párrafo denso y complejo, se huye también del excesivamente simple, puesto que fragmenta el proceso de comprensión textual: en este caso, los párrafos de menos de 50 palabras no llegan al 10\%. Sin embargo, cuando no se ha realizado un proceso de instrucción, el estudiante parece valorar el 
párrafo corto como modelo de procesamiento informativo, de manera que asciende su frecuencia hasta el $24 \%$.

En cualquier caso, se debe llamar la atención sobre el hecho de que el párrafo cognitivamente de mayor frecuencia, y además con diferencia, es el de 51-100 palabras. Podemos apuntar, no obstante, algunos datos más precisos y reveladores. Así, TV ofrece unos resultados según los cuales los párrafos entre 51 y 200 palabras suman el $80 \%$ de los ejemplos; en cambio, en TM el 88\% está entre 1 y 150 palabras: un porcentaje similar se alcanza en una secuencia de constituida sobre una franja inmediatamente inferior. Ello se puede interpretar desde dos hipótesis igualmente plausibles: o bien considerar que la instrucción en expresión escrita supone una tendencia a utilizar párrafos cognitivamente más densos, o bien aceptar que la mayor extensión de un texto, y por ello su carácter informativamente más complejo, tiene efectos en la densidad media de los párrafos que los conforman: TM supone un texto de unas quinientas palabras; enfrente, TV exige una media de mil novecientas. Solo contamos con estos dos ejemplos para este trabajo, de modo que se hace difícil llegar a una conclusión definitiva. No obstante, interesa recordar ahora los datos recabados en el análisis temático de los párrafos: TV se demostraba como mucho más complejo desde esa perspectiva; no es de extrañar que la vaya acompañada de una mayor complejidad conceptual.

\section{Conclusión}

El párrafo no es una unidad canónicamente construida y fijada en la tradición discursiva. Los intentos por obtener una caracterización de esta naturaleza chocan una y otra vez con los datos que nos aporta una realidad que tozudamente desprecia las propuestas de esa naturaleza. El párrafo funciona dentro del contexto de las diferentes estrategias de construcción discursiva y, como tal, se regula dentro de unos límites básicamente flexibles pero también de compleja descripción. Y la complejidad a la que nos referimos deriva de su naturaleza multifuncional. El párrafo disfruta de manera de cuatro grandes dimensiones: temática, visual, retórica y cognitiva. Obviar alguna de ellas es no tener en consideración alguna de las características inherentes a esta unidad. Ciertamente, no se puede atribuir idéntica importancia cualitativa a cada una de ellas, pero no por ello es legítimo obviarlas en el proceso de descripción y caracterización.

El párrafo debe interpretarse como unidad temática compleja, en correlación con el enunciado, considerado como unidad temática simple. Y esto no implica en absoluto defender que el párrafo desarrolla una idea. Entre otras cosas, porque esta postura es esencialmente estéril como base evaluativa en razón de su propia imprecisión. El párrafo pasa a entenderse como unidad informativa compleja dotada de coherencia interna y 
destinada a segmentar la información en beneficio de la organización textual. Desde esta percepción es más sencillo interpretar su dimensión retórica: es el autor quien decide cómo articula las diferentes unidades informativas; desde la intención textual se entiende por qué se hace una distribución de párrafos en un texto, y no otra igualmente posible y aceptable en términos discursivos. El párrafo también responde de alguna manera a la percepción visual que el autor construye de su texto; probablemente esta sea la dimensión más débil y heterogénea pero parece importante considerarla en la medida en que los autores no se preocupan tanto por construir párrafos visualmente similares como por evitar aquellos demasiado cortos o excesivamente largos. Finalmente, el párrafo cumple una función en el procesamiento cognitivo del texto. $Y$ desde esa función se regula la aparente libertad de la que goza el autor a la hora de construir textos. Del mismo modo que se evita fragmentar la comprensión en un número elevado de párrafos conceptualmente muy sencillos, también se escapa de los exageradamente densos en términos cognitivos. El estudio realizado indica la aversión por párrafos inferiores a cincuenta palabras o superiores a doscientas.

Falta aún mucho en el proceso de definición del párrafo. Así, habrá que dedicar esfuerzos a la revisión del concepto de pseudopárrafo, como unidad fallida de construcción textual. También hay trabajo por hacer en lo que toca a la clasificación de tipos de párrafos, para la que será necesario tomar en consideración argumentos de naturaleza cognitiva, conceptual y discursiva; esto es, los mismos que hemos manejado en estas páginas. De la misma manera, es necesario llevar a cabo un análisis pormenorizado del párrafo más allá de los márgenes del texto expositivo, en el cual se han centrado la mayor parte de los investigadores.

Todo ello desde una perspectiva esencialmente aplicada. Buscamos precisar conceptos, aclarar resultados y reflexionar sobre datos que en última instancia nos permitan mejorar la formación de usuarios de la variante escrita del español.

\section{Referencias bibliográficas}

Albadalejo, T. y A. García Berrio (1983): "Estructura composicional. Macroestructuras", Estudios de Lingüistica de la Universidad de Alicante, 1, págs. 127-180.

Bain, A. (1866): English Composition and Rhetoric. London, Longman.

Bolinger, D. (1946): “Visual Morphemes”, Language, 22, págs. 332-340.

Bond, S. \& J. Hayes (1984): "Cues people use to paragraph text", Research in the teaching 
of English, 18, págs. 147-167.

Braddock, R. (1974): "The frequency and placement of topic sentences in expository prose", Research in the Teaching of English, 8, págs. 287-302.

Brooks, C. y R. P. Warren (1949): Modern Rhetoric. New York, Harcourt.

Bustos Gisbert, J. M. (2011): "Errores discursivos y estilísticos en la expresión escrita: categorización y valoración", Quaderns de Filologia, Estudis Linguistics, 16, págs. 41-64.

Calsamiglia, H. y A. Tusón (1999): Las cosas del decir. Barcelona, Ariel.

Cassany, D. (1995): La cocina de la escritura. Barcelona, Anagrama.

Chafe, W. L. (1980): "The Deployment of Consciousness in the Production of a Narrative". En Chafe, W. L. (ed.): The Pear Stories. Cognitive, Cultural and Linguistic Aspects of Narrative Production. Norwood, New Jersey, Ablex, págs. 9-50.

Coulthard, M. (1985): An introduction to discourse analysis. London, Longman.

Crystal, D. (1992): An Encyclopedic Dictionary of Language and Languages. Oxford, Blackwell.

De la Fuente, M. A. (2007): “La aglutinación de párrafos”, Español Actual, 88, págs. 95110.

Figuera, C. (2001): Pragmática de la puntuación. Barcelona, Octaedro.

Fuentes, C. (1996): Aproximación a la estructura del texto. Málaga, Ágora.

Garachana, M. y E. Montolío (2000): “De la oración al párrafo. Del párrafo al texto”. En Montolío, E. (coord.): Manual práctico de escritura académica. Barcelona, Ariel, págs. 69-104.

Gernsbarcher, M. A. y D. Hargreaves (1992): "The privilege of primacy: Experimental data and cognitive explanations”. En Payne, D. (ed.): Pragmatics of word order flexibility. London, John Benjamins, págs. 141-214.

Girón Alconchel, J. L. (1981): Introducción a la explicación lingüística de textos. Metodología y práctica de comentarios lingüísticos. Madrid, Edinumen.

González Cobas, J. (2002): Párrafo y tópico de párrafo en la "Estoria de España" de Alfonso X. Madrid, Universidad Autónoma de Madrid. Tesis Doctoral.

González Cobas, J. (2004): “Estudio sobre el párrafo”, RELUA, 18, págs. 87-106.

González Cobas, J. (2008): “Acerca del tópico de párrafo”, Verba Hispánica, 16, págs. $81-90$.

Green, J. G. y D. I. Noreen (1974): “Time to read semantically related sentences", Memory and Cognition, 2 (1A), págs. 117-120.

Haberlandt, K., C. Brian y J. Sandson (1980): “The episode schema in story processing”, Journal of Verbal Learning and Verbal Behavior, 19, págs. 635-650.

Haliday, M. A. K. y R. Hassan (1976): Cohesion in English. London, Longman. 
Harris, Z. (1952): “Discourse Analysis”, Language, 28, págs. 1-31.

Hayes, E. (2003): “Alexander Bain's Long Shadow. The current traditional paragraph in the classroom". New Histories of Writing IV. Forms and Rhetorics. MMLA Meeting Chicago, IL: http://societyforcriticalexchange.org/includes/pageContent/Archives/ Index/Archives\%20Nevigation.htm (15-12-2010).

Hoffman, T. R. (1989): "Paragraph sans Anaphora", Journal of Pragmatics, 13, págs. 239-250.

JI, S. (2008): "What do paragraph division indicates in narrative texts?", Journal of Pragmatics, 40, págs. 1719-1730.

Knoblauch, C. H. (1981): "The Rhetoric of the paragraph: A reconsideration", Journal of Advanced Composition, 1-2, págs. 53-61.

Larson, R. (1976): "Structure and Form in Non-Fiction Prose". En Tate, G. (ed.): Teaching Composition: 10 Bibliographical Essays. Fort Worth, Christian University Press, págs. 45-71.

Lausberg, H. (1967): Manual de retórica literaria. Madrid, Gredos.

Lázaro, F. (1979): Curso de Lengua española. Madrid, Anaya.

Le, E. (1999):"The use of the paragraphs in French and English academic writing: Towards a grammar of paragraps", Text, 19 (3), págs. 307-343.

Le, E. (2004): "The role of Paragraphs in the construction of coherence, text linguistics and translation studies", IRAL, 42, págs. 259-275.

Longacre, R. E. (1976): An Anatomy of Speech Notions. Lisse, The Peter de Ridder Press.

Longacre, R. E. (1979): “The Paragraph as a Grammatical Unit”. En Givón, T. (ed.): Syntax and Semantics. Discourse and Syntax. London/New York/San Francisco, Academic Press, págs. 115-134.

Longacre, R. E. (1980): "An Apparatus for the Identification of Paragraph Types", Notes on Translation, 15, págs. 5-22.

Martínez, M. (2008): "Criterios de configuración del párrafo en la escritura académica de los estudiantes de educación”, Laurus, 14, págs. 207-225.

Núñez Ladevéze, L. (1997): “Definición funcional de párrafo como unidad de coherencia”, Revista Española de Lingüística, 27 (1), págs. 135-159.

Olivares, C. (1982): "El párrafo: estructura y función”, Cuadernos de investigación filológica, 8, págs. 17-38.

Pérez, Juliá, M. (1998): Rutinas de la escritura. Valencia, Universitat de Valencia.

Popken, R. L. (1987): "A study of topic sentence in academic writing”, Written Communication, 4 (2), págs. 209-228.

Quirk, R., S. Greenbaum, G. Leech y J. Svartik (1972): A Grammar of Contemporary English. London, Longman. 
Sánchez Escobar, A. (1996): "La retórica contrastiva del párrafo inglés y español y sus repercusiones en la enseñanza de inglés escrito”. En Martín Vázquez, M. (coord.): Gramática contrastiva inglés-español. Huelva, Universidad de Huelva.

Serafini, Ma T. (1989): Cómo redactar un tema. Barcelona, Paidós.

Serafini, Ma T. (1994): Cómo se escribe. Barcelona, Paidós.

Smith, C. G. (2008): "Braddock revisited: The frequency and placement of topic sentences in academic writing”, The Reading Matrix, 8 (1), págs. 78-95.

Sorókina, T. (2008a): "De la estructura del párrafo hacia la organización discursiva: consideraciones teórico-prácticas", Revista Iberoamericana de Educación, 45 (5): http://www.rieoei.org/2210.htm. (15-12-2010)

Sorókina, T. (2008b): "El párrafo: las estructuras discursivas", Hesperia, Anuario de Filología Hispánica, 11, págs. 73-85.

Stark, H. (1988): "What do a paragraph markings do", Discourse Processes, 11, págs. 275-303.

Stern, A. (1976): "When is a paragraph", College Composition and Communication, 27 (3), págs. 253-257.

Toulmin, S. (1958): The Uses of Argument. Cambridge, Cambridge University Press.

Werlich, E. (1976): A Text Grammar of English. Heidelberg, Quelle \& Meyer. 